\title{
Formation of Glycerol as Byproduct and its Application During Biodiesel Production From Pongamia Pinnata
}

\author{
Bibhuti B. Samantaray ${ }^{1}$,Rajnikant Choudhary ${ }^{1}$,Amit $\operatorname{Kumar}^{1}$,Wasim Akhtar ${ }^{1}$, \\ Manish Kumar ${ }^{1}$, Susil K. Garanaik ${ }^{1}$

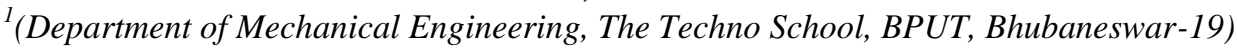

\begin{abstract}
Pongamia Pinnata is the scientific name of Karanja. It is a medium sized tree that is plentily found alloverOdisha. There are a lot of research is going on regarding production of Biodiesel from Karanja oil but the main objective of the paper is the production and implementation of Glycerol from Karanja oil. Alcohol glycerol, a clear, colorless, viscous, sweet-tasting liquid belonging to the family of organic compounds; molecular formula $\mathrm{HOCH}_{2} \mathrm{CHOHCH}_{2} \mathrm{OH}$. In this experiment we have produced Biodiesel as well as Glycerol as a byproduct but we have focused mainly on the formation of the Glycerol and its application. So in a different view point, if the production of value added glycerol can be increased within the same cost of biodiesel production, overall cost of biodiesel can be reduced to an optimum level. The effective utilization of crude glycerol will contribute to the viability of biodiesel. In this experiment, we have taken non edible Karanja oil for preparation of Glycerol by transesterification of crude oil with methanol in presence of $\mathrm{NaOH} / \mathrm{KOH}$ as catalyst and yielded of approximately $11 \%(w / w)$ glycerol.
\end{abstract}

Keywords: Biodiesel,Catalyst, Glycerol,Pongamia Pinnata,Transesterification

\section{Introduction}

A lot of researches are going on, on the production of alternative fuel from renewable sources of energy, they got success also in preparing biodiesel as alternative fuel from renewable resources like vegetable oil and some non-edible oil from plants such as Jatropha, Karanja, Neem, Mahua, Simarouba etc. Earlier, more emphasis was given on the production of biodiesel not on its by-product like glycerol.But at present time, production of biodiesel has been industrialized and that also resulted large scale of by-product formation like Glycerol. So emphasis should be given on proper utilization of by-product from value added application and profitable biodiesel production. InIndia the emphasis is on the non-edible oilplants like Jatropha, Karanja, Neem, Mahua, Simarouba etc for the production of biodiesel as well as glycerol as major by-product.

In India the Karanja tree is found all-over the country, especially in eastern India and Western Ghats [1]. The botanical name of Karanja is Pongamia glabra of Leguminaceae family. Karanja oil has been reported to contain furan flavones, furanoflavonols, chromenoflavones, flavones and furanodiketones which make the oil non-edible and hence further encourages its application for biodiesel production and Glycerol as Byproduct [2].Glycerol or glycerine is a simple polyol (sugar alcohol) compound. It is widely used in pharmaceutical formulations because it is colourless, odourless, viscous liquid [3]. It is soluble in water and hygroscopic in nature because of its three hydroxyl groups. Crude glycerol is the principal by-product of biodiesel production, which is about $11 \% \mathrm{w} / \mathrm{w}$ of Karanja oil.Glycerol is sweet-tasting and of low toxicity. The rate of Biodiesel production around the world is slower than excepted and the main reason is its relatively high production cost. Utilization of the glycerol co-product is one of the promising options for lowering the production cost. In other words, every gallon of biodiesel produced generates approximately 1.05 pounds of glycerol.Fangxia Yang et al. [4] has done a review regarding Crude Glycerol production as a by-product during Biodiesel Production. In this Paper we have focused mainly on the production of the Glycerol and its application. Since purified glycerol is a high-value and commercial chemical with thousands of uses, the crude glycerol presents great opportunities for new applications. For that reason, more attention is being paid to the utilization of crude glycerol from biodiesel production in order to defray the production cost of biodiesel and to promote biodiesel industrialization on a large scale. SimilarlyXiaohu Fan and Rachel Burton [5] have done a review regarding the production of Biodiesel and Glycerol. In their study they have focused on the production of Biodiesel from the Jatropha tree.

$\begin{array}{rlll}3 \mathrm{CH}_{2}-\mathrm{O}-\mathrm{COOH}+ & 3 \mathrm{CH}_{3} \mathrm{OH} & ----> & 3 \mathrm{CH}_{2} \mathrm{OH} \\ \text { (TRIGLYCERIDES) } & \text { (METHNOL) } & \text { (GLYCEROL) } & \text { (ESTER) }\end{array}$

Zaki Y. Zakariaet al. [6] has studied catalytic conversion of glycerol to olefins. In that study it has mentioned the proper utilization of Glycerol in different forms. B.L.A Prabhavathi Devi et al. [7] has found in their experiment $\mathrm{SO} 3 \mathrm{H}$-carbon catalyst from glycerol for the production of biodiesel 


\section{Experimental Setup And Procedure}

2.1 Experimental setup: A schematic of the experimental set-up used for the production of Glycerol is shown in Fig.1. The Experimental setup consistsa heating device, astirrer,a motor, a thermo meter, beaker, separating funnel, washing unit, diffuser unit and chemical unit. A metal frame is being used for holding up the motor and separating funnel at the same time. The crude Karanja oil iskept in the beaker and being heated by the heater with a controlled environment. A stirring rod is dipped into the solution ofKaranja oil and the other chemical mixture like $\mathrm{MeoH}$ and $\mathrm{KoH}$. The equipment like Beaker, Stirring rod, Separating Funnel, Conical Flask are made up of high resistance Glass Material. The stirrer is rotated by an electric motor of variable RPM ranging from $200 \mathrm{rpm}$ to $600 \mathrm{rpm}$. A temperature measuring device i.e. thermometer is dipped in the solution for continuous temperature measurement. The beaker is covered with a glass cover to prevent reactant loss as alcohol being volatile vaporized during the reaction so it is necessary to prevent it from vaporizing. Separatoris used to separate the glycerol from biodiesel after transesterification process.

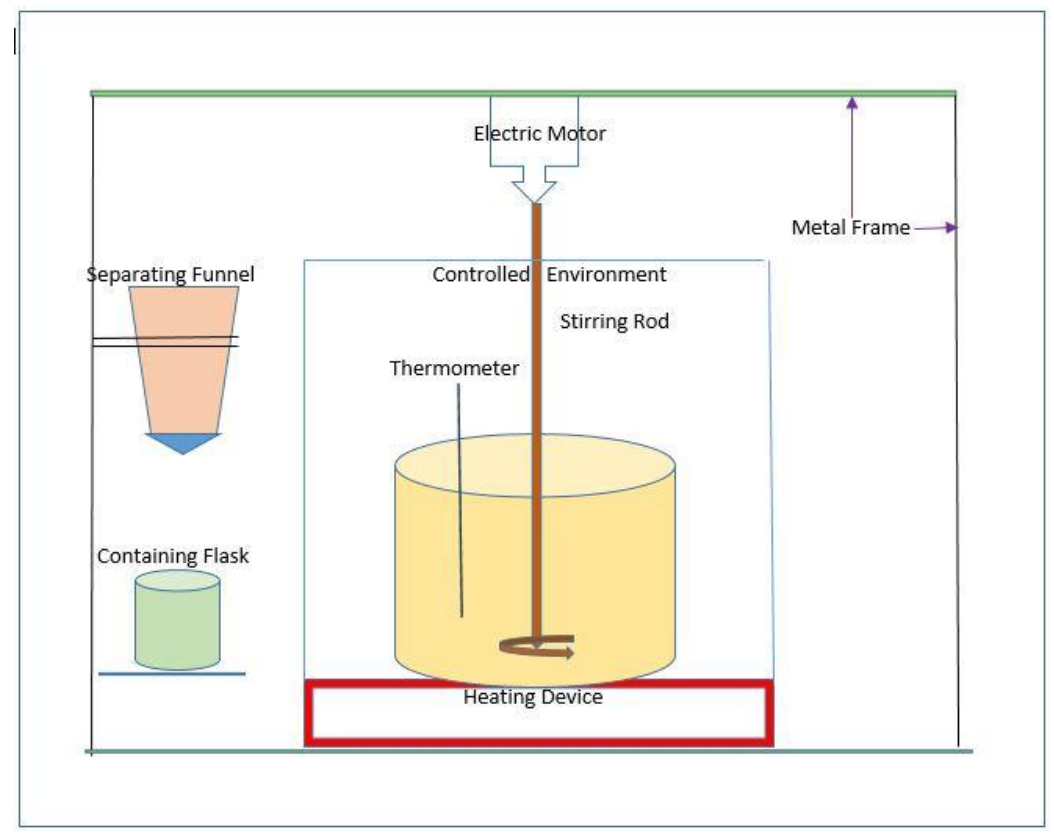

Figure.1. Schematic of the experimental setup

2.2 Experimental procedure:Initially $300 \mathrm{ml}$ of Karanja oil was taken in the beaker and heated at $70^{\circ} \mathrm{c}$ for the removal of moisture. The oil was then allowed to cool down .The transterification process was carried out in a basic medium to achieve it. KOHis being used as catalysthere .The required amount of catalyst; $10 \mathrm{gmKOH}$ was weighed and dissolved completely in $60 \mathrm{ml}$ of methanol by using stirrer provided in the potassium methoxide. The alkali methoxide solution was added into the oil for vigorous mixing by means of a mechanical transesterification vessel. The required temperature of $65-70^{\circ} \mathrm{C}$ was maintained throughout the reaction time of 1.5 hours by means of thermostat arrangement. The cloudy looking free fatty acids, called glycerine, will sink to the bottom and the methyl ester- a translucent liquid, will remain on top. When the separation appears, we should stop mixing and allows the mixture to settle down overnight.The product was put in the separating funnel and the two phases due to different density is separated in separated vessels. The upper layer consist of biodiesel, alcohol, and some soaps (formed due to side reaction saponification-FFA gets converted to soaps) and lower layer consists of crude glycerol with some impurities and excess alcohol. Purification of upper layer can be done by heating the solutionup to $70^{\circ} \mathrm{c}$ and by bubble washing. It is necessaryto purify the lower layer glycerol mixture up to desired level but alcohol can be removed by heating the solution up to $70^{\circ} \mathrm{c}$. The resultant crude glycerol is not highly purified but can be used for several value added application. A Schematic of the whole process is shown below in Fig.2. 


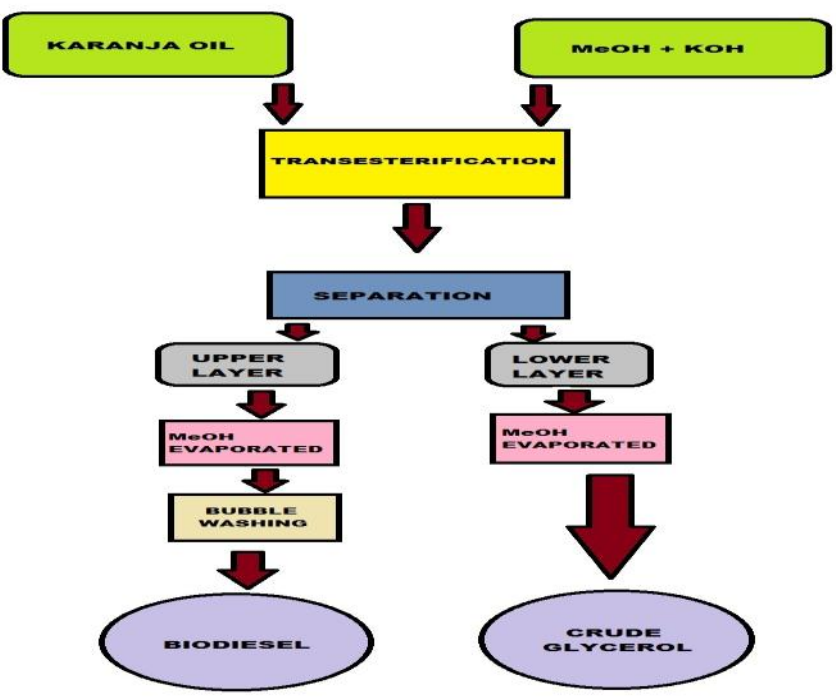

Figure 2. The DetailedBiodiesel and Glycerol Production Process.

\section{Result And Application}

We found that FFA content of Karanja oil is responsible for glycerol formation. Transestification process can beapplied for the production of glycerol. We have obtained a maximum yield of around $11 \%(\mathrm{w} / \mathrm{w})$ Glycerol \& around 88\% Biodiesel from the raw Karanja oil by transestification. The effective use of crude glycerol will contribute to the viability of biodiesel. It is too costly to refine the crude glycerol to a high purity so many researches and studies have conducted for innovative utilization of crude glycerol. Glycerol formed plays a role in determining the cost of the biodiesel as well as production process if formed on large scale. It helps in profitable biodiesel production. Also glycerol has a number of value added applications. Some of the most important are listed:-

- Crude glycerol (without any purification) could be used as a green solvent for organic reactions.

- Crude glycerol could be used as a fuel for generating electricity from microbial fuel cells [8].

- Co-hydrothermal pyrolysis and co-liquefaction of manure with crude glycerol could improve the production yield of bio-oil. However, for the co-liquefaction, too much addition of crude glycerol affected the carbon content and heat value of the bio-oil $[8,9]$.

- In food and beverages, glycerol serves as a solvent, and sweetener, and may help preserve foods.

- It is also used as filler in commercially prepared low-fat foods (e.g., cookies), and as a thickening agent in liqueurs.

- Glycerol and water are used to preserve certain types of leaves.[9]

- Glycerol is used in medical and pharmaceutical and personal care preparations, mainly It is found in allergen immunotherapies, cough syrups, elixirs and expectorants, toothpaste, mouthwashes, skin care products, shaving cream, hair care products, soaps and water-based personal lubricants.

- In solid dosage forms like tablets, glycerol is used as a tablet holding agent.

- Glycerol can be used as a laxative when introduced into the rectum in suppository or small-volume (2-10 $\mathrm{ml}$ ) (enema) form; it irritates the anal mucosa and induces a hyperosmotic effect.[10]

- Taken orally (often mixed with fruit juice to reduce its sweet taste), glycerol can cause a rapid, temporary decrease in the internal pressure of the eye. This can be useful for the initial emergency treatment of severely elevated eye pressure. [11].

- Glycerol is used as a skin moisturizer in soaps and lotions and a softening agent in candy and baked goods [12].

- Glycerol is a good source of carbon and energy for growth of several microorganisms.

IV.

\section{Conclusion}

The study has enabled us to confirm that Karanja oil can be used as a raw material to obtain Glycerol as major by-product during biodiesel production from Karanja oil. Biodiesel can be used as fuel in diesel engine. The engine performance with biodiesel is similar to that of diesel, while emission are less in case of biodiesel. Also glycerol availability has increased tremendously as it arises as by-product of the biodieselprocess. Besides using glycerol as a chemical in creams and other small-scale applications,glycerol may be used as starting material for large-scale biotechnological processes. In this experiment the maximum percentage of biodiesel 
production is around $11 \%$ which shows a good agreement with the previous studies. Though the process of Glycerol production is costly still it lends required support towards the overall cost of the Biodiesel production.

\section{References}

[1] Y.C.Sharma and B. Singh, Development of Biodiesel from Karanja, a tree found in rural India, Fuel 87, (2008) 1740-1742

[2] V.RManilla,M.V. Mallikarjun, G.L.Narayana Rao, Preparation of Biodiesel from Karanja Oil, IJEE, 1, 2011, 94-100

[3] NPachauri and B He, Value Added Utilisation of Crude Glycerol from Biodiesel Production, ASABE, Paper number:-066223

[4] F Yang, M A. Hanna and RSen, Value-Added Uses For Crude-Glycerol-A By-product Of Biodiesel Production, Biotechnology for Biofuel, 2012, 5:13

[5] X Fan and R Burton, Recent Development of Biodiesel Feedstockand the application of Glycerol: A Review, The open fuel \& Energy Science Journal, 1200912, 100-109

[6] Z Y. Zakaria, N A S Amin and J Linnekoski, A perspective on catalytic conversion of glycerol to olefins, Biomass and Bioenergy 55, 2013, 370-385.

[7] B.L.A. Prabhavathi Devi, T V K Reddy, K V Lakshmi and R.B.N. Prasad, A green recyclable SO3H-carbon catalyst derived from glycerol for the production of biodiesel from FFA-containing karanja (Pongamia glabra) oil in a single step,Bioresource Technology 153, 2014, 370-373

[8] Feng Y, Yang Q, Wang X, Liu Y, Lee H, Ren N: Treatment of biodiesel production wastes with simultaneous electricity generation using a single-chamber microbial fuel cell. BioresourTechnol102, 2011, 411-415

[9] Xiu S, Shahbazi A, Shirley V, Mims MR, Wallace CW: Effectiveness and mechanisms of crude glycerol on the biofuel production from swine manure through hydrothermal pyrolysis. J Anal Appl Pyrolysis 87, 2010, 194-198.

[10] "Glycerin Enema" (http://www.drugs.com/cdi/glycerin-enema.html). Drugs.com. Retrieved 2012-11-17.

[11] "Glycerin (Oral Route)" (http://www.mayoclinic.com/health/drug-information/DR601713). Mayo Foundation for MedicalEducation and Research. Retrieved 2012-11-17.

[12] "Glycerin in Bath Salts - Health Benefits for the Skin" (http://homemadebathsaltsrecipes.blogspot.com/2012/03/glycerinin-bathsalts-health-benefits.html). Homemade Bath Salts Recipes. Retrieved 22 February 2013. 